\title{
Profiteren van andermans wanprestatie
}

\author{
Beschouwingen naar aanleiding van HR 28 maart 2014, ECLI:NL:HR:2014:740, \\ NJ 2014/194 (Joba/Tjin-Hin-Tjoe)
}

\author{
Mr.drs. A.M.M. Hendrikx*
}

\begin{abstract}
1 Inleiding
Overeenkomsten gelden tussen partijen, maar uit de rechtspraak blijkt dat derdenbelangen vaak - en wellicht zelfs steeds vaker - een rol spelen. Te denken valt aan de doorwerking van exoneratieclausules jegens derden, ${ }^{1}$ een wanprestatie van een contractspartij die tevens een onrechtmatige daad oplevert jegens een derde $^{2}$ en het profiteren van andermans wanprestatie door een derde. Dit artikel gaat in op deze laatste categorie.

Soms zal de partij jegens wie wanprestatie is gepleegd niet alleen de wanpresterende partij moeten aanspreken om haar belangen voldoende te kunnen beschermen, maar ook de derde die bij de wanprestatie is betrokken. Het enkele profiteren van andermans wanprestatie door een derde is op zichzelf genomen niet onrechtmatig. ${ }^{3}$ Een illustratie hiervan biedt het thans te bespreken arrest van 28 maart 2014 inzake Joba/TjinHin-Tjoe ${ }^{4}$ waarin de Hoge Raad heeft bevestigd dat, naast wetenschap van de wanprestatie, bijzondere omstandigheden vereist zijn om te oordelen dat het profiteren van andermans wanprestatie onrechtmatig is. In de ogen van de Hoge Raad is een belangenafweging tussen de benadeelde en de profiterende derde hierbij een aandachtspunt.
\end{abstract}

In het navolgende zal eerst stil worden gestaan bij de feiten en het procesverloop van het arrest van 28 maart 2014 (Joba/ Tjin-Hin-Tjoe) (par. 2). Voorafgaande aan de analyse van het arrest besteed ik aandacht aan de bestaande rechtspraak over het profiteren van andermans wanprestatie (par. 3). Vervol-

\footnotetext{
* Mr. drs. A.M.M. Hendrikx is Professional Support Lawyer bij Clifford Chance te Amsterdam en is als promovenda en docente verbonden aan het Instituut voor Privaatrecht van de Universiteit Leiden.

1. Zie bijv. HR 26 november 2010, NJ 2010/636.

2. Zie bijv. HR 20 januari 2012, NJ 2012/59 en HR 21 december 2012, NJ 2013/46.

3. HR 12 januari 1963, NJ 1962/246 m.nt. H.E. Bröring; C.E. du Perron, Overeenkomst en derden: een analyse van de relativiteit van de contractswerking, Deventer: Kluwer 1999, p. 136; L.M. van Bochove, Betrokkenheid van derden bij contractbreuk. Rotterdam: Erasmus University Rotterdam 2013, p. 29 (te raadplegen via: <http:// hdl. handle. net/1765/ 50174>).

4. HR 28 maart 2014, ECLI:NL:HR:2014:740, NJ 2014/194, (Joba/TjinHin-Tjoe).
}

gens maak ik enige opmerkingen over het arrest en de bijzondere omstandigheden die de handelwijze van een profiterende derde onrechtmatig kunnen maken (par. 4). Afgesloten wordt met een conclusie (par. 5).

\section{Casus en procedureverloop}

\subsection{Defeiten}

Vanaf 1 januari 1990 huurt Tjin-Hin-Tjoe van Ram Properties B.V. de winkelruimte op de begane grond van het pand aan de Eerste van der Helststraat 64 te Amsterdam (hierna: het pand). Op de achterzijde van het exemplaar van het huurcontract van Tjin-Hin-Tjoe staat met potlood bijgeschreven: 'Indien de verhuurder het pand wil verkopen, zal de eerste partij aan welke hij het pand dient aan te bieden, de huurder zijn. De huurder dient binnen twee weken hierover uitsluitsel te geven.'

Op 18 januari respectievelijk 24 januari 2007 verkoopt Ram Properties vijftien panden, waaronder het pand waarin Tjin-Hin-Tjoes winkel is gevestigd, aan Joba Trust B.V. (hierna: Joba). Ram Properties stelt Tjin-Hin-Tjoe hiervan niet op de hoogte. Eveneens op 24 januari 2007 verkoopt Joba vier van de gekochte panden, waaronder het pand van Tjin-HinTjoe, door aan een derde, Lugt. Komt Joba de aangegane leveringsverplichting niet na, dan dient zij een boete van tien procent van de koopsom te betalen aan Lugt.

Op 12 februari 2007 heeft Ram Properties een brief gestuurd aan Tjin-Hin-Tjoe waarin staat vermeld dat 'per 23 februari 2007 het pand is verkocht' (leveringsdatum). Naar aanleiding hiervan heeft (een vertegenwoordiger van) Tjin-Hin-Tjoe op 19 en 20 februari 2007 contact gezocht met Ram Properties en de makelaar, waarbij Tjin-Hin-Tjoe zich beroept op zijn voorkeursrecht.

Ram Properties en Joba passeren op 20 februari 2007 om 10:10 uur een notariële koopakte, waarin 23 februari 2007 als leveringsdatum wordt genoemd voor alle aan Joba verkochte panden. Later op de dag, om 18:45 uur, levert Ram Properties uitsluitend het pand waarin de winkel van Tjin-Hin-Tjoe is 
gevestigd vervroegd aan Joba. Dit om te voorkomen dat Ram Properties wanprestatie zou plegen jegens Joba, bijvoorbeeld als gevolg van beslaglegging door Tjin-Hin-Tjoe. ${ }^{5}$ Aansluitend, om 18:50 uur levert Joba eveneens het pand vervroegd door aan Lugt.

\subsection{Het procesverloop}

\subsubsection{Lagere instanties}

Op 5 augustus 2008 vordert Tjin-Hin-Tjoe bij de kantonrechter te Amsterdam een verklaring voor recht dat Ram Properties wanprestatie heeft gepleegd door het in de huurovereenkomst opgenomen voorkeursecht niet na te leven en dat Joba en Lugt onrechtmatig hebben gehandeld tegen hem door te profiteren van de wanprestatie van Ram Properties. Bovendien vordert Tjin-Hin-Tjoe dat Ram Properties, Joba en Lugt hoofdelijk veroordeeld worden tot betaling van een schadevergoeding. Uiteindelijk komt in een afzonderlijke procedure tegen Ram Properties vast te staan dat Ram Properties wanprestatie jegens Tjin-Hin-Tjoe heeft gepleegd door het voorkeursrecht van Tjin-Hin-Tjoe te schenden. ${ }^{6}$

De vorderingen van Tjin-Hin-Tjoe tegen Joba en Lugt worden daarentegen door de kantonrechter afgewezen. Naar het oordeel van de kantonrechter is komen vast te staan dat het voorkeursrecht met potlood is geschreven op het huurcontract van Tjin-Hin-Tjoe, maar niet vermeld stond op de achterzijde van het exemplaar van de huurovereenkomst van Ram Properties. De kantonrechter oordeelt dat noch gesteld noch gebleken is dat Joba en Lugt ten tijde van het sluiten van de koopovereenkomst op 18 respectievelijk 24 januari 2007 al wetenschap hadden, dan wel behoorden te hebben, van het voorkeursrecht van koop van Tjin-Hin-Tjoe. Op 20 februari 2007 raakt Joba bekend met het voorkeursrecht. Op dat moment is er al een leveringsverplichting ontstaan jegens Lugt die Joba dient na te komen op straffe van een boete van tien procent van de koopsom. De kantonrechter oordeelt dat de medewerking van Joba aan de vervroegde levering door Ram Properties niet als onrechtmatig kan worden aangemerkt. Hetgeen Joba in het maatschappelijk verkeer jegens Tjin-HinTjoe betaamt, gaat naar het oordeel van de kantonrechter niet zo ver dat Joba diens belang bij het uitoefenen van persoonlijke rechten tegenover Ram Properties zou moeten laten prevaleren boven haar eigen contractuele verplichtingen jegens Lugt. Naar het oordeel van de kantonrechter zijn Joba en Lugt niet aansprakelijk voor de schade van Tjin-Hin-Tjoe als gevolg van het niet kunnen uitoefenen van diens voorkeursrecht.

Tjin-Hin-Tjoe gaat hiertegen in hoger beroep. In tegenstelling tot de kantonrechter verklaart het hof voor recht dat Joba en

5. Terecht merkt A-G Spier in zijn conclusie op dat het speculatief is wat Tjin-Hin-Tjoe zou hebben gedaan wanneer hij van de vervroegde levering op de hoogte zou zijn geweest (sub 3.2). Hierbij merkt hij op dat Tjin-Hin-Tjoe waarschijnlijk geen beslag zou hebben gelegd, mede gelet op de (risico)aansprakelijkheid wegens het onterecht leggen van beslag.

6. Zie HR 15 juni 2012, ECLI:NL:HR:2012:BW3210.
Lugt jegens Tjin-Hin-Tjoe wel onrechtmatig hebben gehandeld door te profiteren van de wanprestatie van Ram Properties, welk onrechtmatig handelen daaruit bestaat dat zij hun medewerking hebben verleend aan de vervroeging van de levering van 23 februari 2007 naar 20 februari 2007. Het hof overweegt dat Joba en Lugt op 20 februari 2007 wetenschap hadden van het voorkeursrecht van Tjin-Hin-Tjoe en bewust hebben meegewerkt aan de vervroegde levering om beslaglegging door Tjin-Hin-Tjoe te voorkomen. ${ }^{7}$ Het hof meent dat het voor Tjin-Hin-Tjoe van groot belang was het voorkeursrecht te kunnen uitoefenen in verband met de voortzetting van zijn bedrijf en dat hij door de vervroegde levering niet de mogelijkheid heeft gekregen om tot 23 februari 2007 maatregelen te treffen ter bescherming van zijn aanspraken uit het voorkeursrecht. Naast het belang van nakoming van de overeenkomsten, blijkt uit niets dat het voor Joba en Lugt bezwaarlijk was om tot 23 februari 2007 - de afgesproken leveringsdatum - met het voorkeursrecht van Tjin-Hin-Tjoe rekening te houden. Door hun eigen belang te dienen, hebben Joba en Lugt het voorkeursrecht van Tjin-Hin-Tjoe ernstig bekort, aldus het hof. ${ }^{8}$ Daarop veroordeelt het hof partijen tot vergoeding van de door Tjin-Hin-Tjoe geleden schade, nader op te maken bij staat.

\subsubsection{Hoge Raad}

Joba gaat in cassatie, Lugt niet. ${ }^{9}$ De cassatiemiddelen van Joba komen erop neer dat het hof niet voldoende duidelijk heeft gemaakt welke bijkomende omstandigheden ten grondslag liggen aan het oordeel dat Joba onrechtmatig heeft gehandeld door te profiteren van de wanprestatie van Ram Properties. Daarnaast voert Joba aan dat de wetenschap die eerst opkomt na het sluiten van de obligatoire koopovereenkomst niet relevant is. Tevens benadrukt Joba dat het voorkeursrecht van koop een (voorwaardelijke) aanbiedingsplicht inhield.

In cassatie staat vast dat Joba pas na het sluiten van de koopovereenkomsten met zowel Ram Properties als Lugt op de hoogte is geraakt van het voorkeursrecht van Tjin-Hin-Tjoe (r.o. 3.4). Dit betekent naar het oordeel van de Hoge Raad niet dat Joba de nakoming van die overeenkomsten - de overeenkomst met Ram Properties en de overeenkomst met Lugt - niet mocht nastreven door middel van vervroeging van de levering van het pand door Ram Properties aan Joba en de vervroegde doorlevering van het pand door Joba aan Lugt. Dat Joba op het moment van uitvoering van de overeenkomst op de hoogte was van het voorkeursrecht doet hier niet aan af. De Hoge Raad wijst erop dat wanneer de derde na het sluiten van de obligatoire overeenkomst, maar vóór de levering op de hoogte rakt van de wanprestatie van zijn wederpartij dit niet belemmert dat de derde alsnog levering van het verkochte

7. Hof Amsterdam 22 januari 2013, ECLI:NL:GHAMS:2013:BZ4888, r.o. 4.6-4.8.

8. Hof Amsterdam 22 januari 2013, ECLI:NL:GHAMS:2013:BZ4888, r.o. 4.9 .

9. Het is opmerkelijk dat Lugt in het arrest van het hof heeft berust. Hiermee is komen vast te staan dat Lugt aansprakelijk is jegens Tjin-HinTjoe, terwijl Joba wellicht de dans ontspringt. 
goed mag vorderen. ${ }^{10}$ Een zodanige handelwijze kan onder bijzondere omstandigheden evenwel onrechtmatig zijn jegens degene (in casus Tjin-Hin-Tjoe) die een voorkeursrecht heeft dat daardoor wordt gefrustreerd. Hierbij valt, zo overweegt het rechtscollege, met name te denken aan het geval dat sprake is van onevenredigheid tussen het belang bij nakoming van de koopovereenkomsten en het belang dat bestaat bij het kunnen uitoefenen van het voorkeursrecht. Dergelijke omstandigheden heeft het hof volgens de Hoge Raad niet in zijn oordeel betrokken. De Hoge Raad wijst er daarbij op dat Joba heeft gesteld dat zij belang erbij had de jegens Lugt aangegane leveringsverplichting na te komen, waartoe zij zich volgens haar op straffe van een boete van tien procent van de koopsom had verbonden. Het Hof Amsterdam heeft naar het oordeel van de Hoge Raad onvoldoende acht geslagen op deze stelling van Joba en heeft deze omstandigheid niet in zijn oordeelsvorming betrokken. De Hoge Raad verwijst het geding vervolgens naar het Hof Den Haag ter verdere behandeling en beslissing.

\section{Ontwikkeling in de rechtspraak inzake het profiteren van andermans wanprestatie}

Alvorens de analyse van het onderhavige arrest nader uit te werken, zal ik eerst kort de relevante jurisprudentie uiteenzetten. Deze paragraaf biedt een overzicht van de ontwikkeling van de opvattingen van de Hoge Raad inzake het juridische vraagstuk van het profiteren van andermans wanprestatie.

Een derde kan onrechtmatig handelen door zijn medewerking te verlenen aan de wanprestatie van een van de contractspartijen, waardoor een overeenkomst een zekere mate van 'derdenwerking' krijgt. Een klassiek arrest in dit verband is het Pos/ Van den Bosch-arrest uit 1967. ${ }^{11}$ De feiten in dit arrest lagen als volgt. Van den Bosch pacht enige percelen weiland van de familie Brouwer. In de pachtovereenkomst is vastgelegd dat Van den Bosch het recht heeft het perceel (de percelen weiland en de boerderij) te kopen indien het langstlevende familielid komt te overlijden. Wanneer Neeltje Brouwer, het langstlevende familielid, komt te overlijden en Van den Bosch gebruik wil maken van zijn voorkeursrecht, blijkt dat Neeltje Brouwer het perceel inmiddels heeft geschonken aan haar achterneef Rolf Pos, met wie zij een bijzondere vertrouwensrelatie had. Heeft Pos hiermee onrechtmatig gehandeld jegens Van den Bosch?

Naar het oordeel van de Hoge Raad kan onder omstandigheden bij het schenden van een voorkeursrecht niet alleen sprake zijn van een toerekenbare tekortkoming van de verpachter, maar ook van een onrechtmatige daad van degene die de verpachte grond heeft gekregen (in casu Pos). Vervolgens oordeelt de Hoge Raad dat Pos jegens Van den Bosch onrechtmatig heeft gehandeld. Een drietal omstandigheden is daarbij relevant:

10. HR 28 maart 2014, ECLI:NL:HR:2014:740, r.o. 3.4, NJ 2014/194 (Joba/Tjin-Hin-Tjoe).

11. HR 17 november 1967, NJ 1968/42 m.nt. G.J. Scholten (Pos/Van den Bosch).
1. Pos kende de koopoptie.

2. Pos moet zich bewust zijn geweest van het aanmerkelijke nadeel dat Van den Bosch zou lijden, indien het hem onmogelijk zou worden gemakt gebruik te maken van de koopoptie.

3. De bijzondere vertrouwenspositie die Pos ten opzichte van de 86-jarige Neeltje Brouwer innam en de invloed die hij op haar kon uitoefenen.

In zijn vervolgoverwegingen gaat de Hoge Raad vervolgens mee in het eerdere oordeel van het hof inhoudende dat Pos veroordeeld dient te worden tot een passende vorm van schadevergoeding, namelijk het overdragen van het perceel aan Van den Bosch tegen betaling van de geschatte waarde. Aldus blijkt uit het arrest Pos/Van den Bosch dat onder omstandigheden de derde onrechtmatig kan profiteren van andermans wanprestatie, ter zake waarvan schadevergoeding kan worden toegekend, die eruit kan bestaan dat de verplichting tot levering alsnog wordt opgelegd (vgl. art. 6:103 BW).

De in het arrest Pos/Van den Bosch ingezette lijn wordt voortgezet in het in 1985 gewezen arrest Curaçao/Boyé. ${ }^{12}$ Een koper van een stuk grond weigert een (ketting)beding te eerbiedigen waarmee het onroerend goed is belast. Het beding voorziet erin dat de koper een zeker bedrag moet betalen aan de voormalige eigenaar (Boyé), zijn erfgenamen en rechthebbenden voor iedere ton mest- of delfstoffen die in de toekomst van het verkochte land mochten worden gewonnen. In het arrest komt vervolgens de vraag aan de orde of de koper (derde) verplicht is zich aan het beding te houden waarmee het onroerend goed is belast, op straffe van aansprakelijkheid uit onrechtmatige daad wegens het profiteren van wanprestatie. De Hoge Raad staat stil bij de omstandigheden die van belang kunnen zijn voor het onrechtmatigheidsoordeel. Voor de vraag of de derde (koper) in de gegeven omstandigheden door zo te handelen - het niet eerbiedigen van het (ketting)beding - onrechtmatig handelde jegens de benadeelde (de oorspronkelijke eigenaar of zijn rechtsopvolgers onder algemene titel) is naar het oordeel van de Hoge Raad in de eerste plaats beslissend wat de koper wist en moest weten ten tijde van de aankoop van het onroerend goed, en niet wat hij wist toen werd geleverd. In de tweede plaats is de voorzienbaarheid en de ernst van het nadeel dat de erven Boyé zouden lijden en het te verwachten voordeel voor de koper van belang. Als laatste gezichtspunt noemt de Hoge Raad de mate waarin de koper de wanprestatie van de verkoper heeft bevorderd. Het arrest Curaçao/Boyé leert dat, naast wetenschap van het bestaan van de contractuele verplichting van de ander ten tijde van de koop, ook bijkomende bijzondere omstandigheden vereist zijn voor het aannemen van onrechtmatigheid. ${ }^{13}$

12. HR 17 mei 1985, NJ 1986/760 m.nt. C.J.H. Brunner en W.M. Kleijn (Curaçao/Boyé).

13. HR 17 mei 1985, r.o. 3.3, NJ 1986/760 m.nt. C.J.H. Brunner en W.M. Kleijn (Curaçao/Boyé). 
Zo was de toestand tot 1990. In het in 1989 gewezen arrest Scheerders/Van Hoek betreft het - evenals in het arrest Joba/ Tjin-Hin-Tjoe - een geval van dubbele verkoop van onroerend goed. ${ }^{14}$ Uit het arrest blijkt dat de omstandigheid dat de derde pas in een later stadium - na het sluiten van de overeenkomst en voor het verlijden van de notariële akte - op de hoogte is van de wanprestatie van zijn wederpartij, niet zonder meer tot aansprakelijkheid leidt van de derde, indien de derde toch besluit zijn reeds gesloten overeenkomst na te komen. Of dergelijk handelen jegens de benadeelde onrechtmatig is, hangt af van de omstandigheden van het geval. Het arrest staat stil bij het toetsingsmoment waarop de profiterende derde zich bewust dient te zijn van de wanprestatie. De Hoge Raad wijst erop dat het moment van uitvoering van de overeenkomst onder omstandigheden ook als toetsingsmoment kan gelden voor het kennisvereiste, ${ }^{15}$ maar in de visie van de Hoge Raad is er geen sprake van onrechtmatig handelen jegens de benadeelde op de enkele grond dat de derde zich dan bewust is van de wanprestatie. Dus ook in het geval dat de derde zich laat leveren, terwijl de derde zich ervan bewust is dat de zaak reeds aan een ander is verkocht, dienen bijkomende omstandigheden te worden aangetoond om het handelen van de derde als onrechtmatig te kunnen kwalificeren.

\section{Beknopte analyse van het arrest Joba/Tjin-Hin- Tjoe en de bijzondere omstandigheden}

De Hoge Raad bevestigt in het arrest Joba/Tjin-Hin-Tjoe zijn vaste rechtspraak op het terrein van het profiteren van andermans wanprestatie: voor onrechtmatigheid zijn zowel wetenschap als bijzondere omstandigheden vereist. ${ }^{16}$ In beginsel is het toetsingsmoment waarop de derde zich bewust dient te zijn van de wanprestatie, het moment waarop de derde de overeenkomst sluit met de contractbrekende partij. Uitgangspunt daarbij is dat wanneer de koper ten tijde van het aangaan van de koopovereenkomst niet bekend is met een eventueel voorkeursrecht van de huurder, het de koper in beginsel vrijstaat om de nakoming van de koopovereenkomst na te streven door vervroeging van de levering. Een dergelijke handelwijze kan echter alsnog onrechtmatig zijn wanneer de koper in de uitvoeringsfase van de overeenkomst - dus voorafgaand aan de levering - alsnog bekend raakt met de wanprestatie van de wederpartij. De Hoge Raad benadrukt daarbij dat bijzondere omstandigheden vereist zijn voor het aannemen van een dergelijke onrechtmatigheid (r.o. 3.4). ${ }^{17}$ Du Perron stelt zelfs dat alleen bijkomende omstandigheden van bijzonder gewicht in een dergelijk geval tot onrechtmatigheid zullen kunnen lei-

14. HR 8 december 1989, NJ 1990/217 (Scheerders/Van Hoek).

15. Zie HR 8 december 1989, r.o. 3.2, NJ 1990/217 (Scheerders/Van Hoek); Du Perron 1999, p. 153; J.L.P. Cahen, Overeenkomsten en derden, Deventer: Kluwer 2004, p. 9.

16. HR 17 november 1967, NJ 1968/42 m.nt. G.J. Scholten (Pos/Van den Bosch); HR 17 mei 1985, r.o. 3.3, NJ 1986/760 m.nt. C.J.H. Brunner en W.M. Kleijn (Curaçao/Boyé); HR 8 december 1989, r.o. 3.2, NJ 1990/217 (Scheerders/Van Hoek); HR 23 december 2005, r.o. 3.2, NJ 2006/33(Van Oosterom/Baas-Van Oosterom); HR 26 januari 2007, r.o. 3.4, NJ 2007/78 (Van de Ven/Sleegers).

17. Zie ook HR 8 december 1989, r.o. 3.2, NJ 1990, 217 (Scheerders/Van Hoek). den. ${ }^{18}$ Concreet noemt de Hoge Raad in het onderhavige arrest de omstandigheid dat sprake is van onevenredigheid tussen het belang bij nakoming van de koopovereenkomst(en) en het belang dat bestaat bij het kunnen uitoefenen van het voorkeursrecht (r.o. 3.4). Dergelijke omstandigheden - van bijzonder gewicht - kunnen het profiteren van andermans wanprestatie onrechtmatig maken.

De jurisprudentie biedt de nodige aanknopingspunten om een beeld te krijgen van de bijzondere omstandigheden die de handelwijze van een profiterende derde onrechtmatig kunnen maken. ${ }^{19} \mathrm{Zo}$ is het uitlokken of bevorderen van de wanprestatie een omstandigheid die van belang kan zijn voor het onrechtmatigheidsoordeel. ${ }^{20}$ Van uitlokking is sprake indien de derde opzettelijk het initiatief neemt tot het plegen van wanprestatie. Heeft de derde de wanprestatie opzettelijk uitgelokt en is het voor de derde voorzienbaar dat bij de wederpartij van de wanpresterende partij nadeel zal ontstaan, dan handelt de derde onrechtmatig jegens de benadeelde. ${ }^{21}$ In beginsel leveren dergelijke omstandigheden dus een onrechtmatige daad op, tenzij de derde een geslaagd beroep kan doen op een rechtvaardigingsgrond. ${ }^{22}$ Van een lichtere variant is sprake indien de derde de wanprestatie heeft bevorderd. ${ }^{23}$ In dat geval heeft de derde wel aanzienlijk bijgedragen aan de wanprestatie, maar niet het initiatief ertoe genomen. ${ }^{24}$ Ook als de derde de wanprestatie niet zelf (mede) heeft veroorzaakt, kan zijn handelen jegens de benadeelde partij onrechtmatig zijn. Er is dan sprake van het welbewust gebruik maken van de wanprestatie waarbij de bijzondere omstandigheden bepalend zijn voor het onrechtmatigheidsoordeel.

Daarnaast is de relatie tussen de derde en de benadeelde ook een omstandigheid die van belang kan zijn voor het onrechtmatigheidsoordeel. ${ }^{25}$ Men kan hierbij denken aan de verhou-

18. Du Perron 1999, p. 153.

19. Zie voetnoot 16 voor een aantal relevante arresten.

20. Du Perron 1999, p. 151; Van Bochove 2013, p. 52 e.v.; HR 17 mei 1985, r.o. 3.3, NJ 1986/760 m.nt. C.J.H. Brunner en W.M. Kleijn (Curaçao/ Boyé).

21. Du Perron 1999, p. 149; HR 8 januari 2010, concl. A-G Langemeijer, sub 2.9, NJ 2010/187 m.nt. M.R. Mok (ARN/Multicar). Zie voor een andere opvatting: H.J.S.M. Langbroek, Gebruikmaken van wanprestatie: (n)iets nieuws onder de zon?, MvV 2010, nr. 3, p. 53.

22. Deze opvatting sluit aan bij de wettelijke regeling van botsende rechten op levering (art. 3:298 BW). Joba staat hierbij stil in haar cassatiemiddelen. Dit punt zal in deze bijdrage verder buiten beschouwing worden gelaten. Voor een kritische bespreking hiervan wordt verwezen naar de annotatie van M. Malycha (JOR 2014/189).

23. Du Perron 1999, p. 150; Van Bochove 2013, p. 52 e.v.

24. Hierbij kan men denken aan de situatie dat de derde aan zijn wederpartij middelen verschaft om wanprestatie te plegen, bijvoorbeeld door af te spreken dat de derde de nadelige gevolgen van de wanprestatie voor zijn rekening zal nemen (HR 18 juni 1971, NJ 1971/408 (Bruurs/Haagen)). In dat geval is er sprake van ongeoorloofde bevordering van de wanprestatie, hetgeen onrechtmatig is. Zie Du Perron 1999, p. 151 en Van Bochove 2013, p. 53.

25. Zie ook HR 23 december 2005, r.o. 3.2, NJ 2006/33 (Van Oosterom/ Baas-Van Oosterom), waar de Hoge Raad wijst op de 'bijzondere vertrouwenspositie' van Van Oosterom. 
ding overheid-burger ${ }^{26}$ of een concurrentieverhouding. ${ }^{27}$ In het laatste geval kunnen er andere normen tussen partijen gelden. ${ }^{28}$ Het vrije verkeer van handel en bedrijf houdt immers in dat eenieder in het economische verkeer in zijn eigen voordeel mag handelen en daarbij de overige marktpartijen mag beconcurreren. ${ }^{29}$ Het aansprakelijkheidsrecht mag niet zo ver gaan dat de concurrentievrijheid al te veel aan banden wordt gelegd.

Een dikwijls terugkerende bijzondere omstandigheid die een handelwijze van de derde onrechtmatig kan maken, is de ernst en de voorzienbaarheid van het nadeel dat wordt geleden door de getroffene als gevolg van de wanprestatie. ${ }^{30}$ De omstandigheden van het geval zijn daarbij van belang om te concluderen of het nadeel van grote betekenis is voor de getroffene. Het voordeel van de derde, ontstaan door de wanprestatie, kan hierbij als richtsnoer dienen voor het vaststellen van het nadeel dat de benadeelde heeft geleden. ${ }^{31}$

De hiervoor genoemde bijzondere omstandigheden komen naar voren in het arrest Joba/Tjin-Hin-Tjoe. In cassatie heeft Joba aangevoerd dat door het hof niet is vastgesteld dat Joba de wanprestatie van Ram Properties heeft uitgelokt of bevorderd (sub 3.3.3). Van uitlokking of (ongeoorloofde) bevordering lijkt in casu geen sprake te zijn. Maar het gegeven dat Joba heeft meegewerkt aan de vervroeging van de levering van het pand - vanwege de angst voor een mogelijke beslaglegging door Tjin-Hin-Tjoe en het niet kunnen nakomen van haar leveringsverplichting jegens Lugt op straffe van een boete van tien procent van de koopsom $^{32}$ - kan wel als bijzondere omstandigheid meewegen. Deze omstandigheid kan, samen met de hierna te bespreken omstandigheden, bijdragen tot het antwoord op de vraag of Joba onrechtmatig heeft gehandeld jegens Tjin-Hin-Tjoe door te profiteren van de wanprestatie van Ram Properties.

Het hof lijkt veel gewicht te hebben toegekend aan het (grote) belang van Tjin-Hin-Tjoe dat is gelegen in 'waarborging van de continuïteit van zijn onderneming in het door hem gehuurde pand' (r.o. 4.9). Het hof heeft daarbij gewezen op het mogelijke risico voor Tjin-Hin-Tjoe eruit bestaande dat hij zou worden geconfronteerd met een opvolgende verhuurder

26. HR 27 januari 1989, NJ 1990/89 m.nt. C.J.H. Brunner (Verboom/ Staat).

27. Van Bochove 2013, p. 277-278.

28. De omstandigheid dat sprake is van een concurrentieverhouding is van belang voor het onrechtmatigheidsoordeel. In het arrest ARN/Multicar (HR 8 januari 2010, NJ 2010/187 m.nt. M.R. Mok) makt de Hoge Raad een onderscheid tussen de situatie waarin een vordering wordt ingediend door een distributeur of door een concurrent tegen de profiterende derde. Afhankelijk van de omstandigheden van het geval gelden andere normen voor onrechtmatigheid.

29. Van Bochove 2013, p. 41-42; Du Perron 1999, p. 147-149.

30. HR 17 november 1967, NJ 1968/42 m.nt. G.J. Scholten (Pos/Van den Bosch); HR 17 mei 1985, NJ 1986/760 m.nt. C.J.H. Brunner en W.M. Kleijn (Curaçao/Boyé); HR 15 oktober 1999, NJ 2000/101 m.nt. A.R. Bloembergen (Driessen/Benegas).

31. HR 4 juni 1965, NJ 1965/381 (Kamsteeg/Caltex).

32. Zie ook Hof Amsterdam 22 januari 2013, ECLI:NL:GHAMS: 2013:BZ4888, r.o. 4.6. die de huurovereenkomst en daarmee zijn recht om het pand te gebruiken, zou willen beëindigen. In zijn conclusie voor het arrest van de Hoge Raad (sub 3.7.1) merkt A-G Spier evenwel op dat uit de door het hof vastgestelde feiten en omstandigheden niet kan worden afgeleid dat er sprake was van een groot belang aan de zijde van Tjin-Hin-Tjoe. Bovendien wijst de A-G erop dat aan Tjin-Hin-Tjoe als huurder van het pand de bescherming toekomt van art. 7:226 lid 1 BW ('koop breekt geen huur').

Het dienen van het eigen belang door Joba zal gezien de vrije concurrentie in het economische verkeer op zichzelf genomen niet (spoedig) onrechtmatig zijn. Bovendien heeft Joba, door nakoming van de met Lugt gesloten koopovereenkomst na te streven, juist voorkomen dat zij een aanzienlijke boete zou verbeuren en dus nadeel zou lijden. Niet voor niets heeft de Hoge Raad in de eindstrofe van zijn arrest overwogen dat het oordeel van het hof dat het handelen van Joba jegens Tjin-HinTjoe onrechtmatig was, nadere motivering behoeft. Het rechtscollege verwijst daarbij expliciet naar de stelling van Joba waarin zij zich op het standpunt stelt dat zij er belang bij had de jegens Lugt aangegane leveringsverplichting na te komen, waartoe Joba zich, naar eigen zeggen, op straffe van een boete van tien procent van de koopsom had verbonden. Een en ander doet uiteraard niets af aan het belang van Tjin-HinTjoe om het door hem bedongen voorkeursrecht tot koop uit te kunnen oefenen en aldus de continuïteit van zijn onderneming voor de toekomst veilig te stellen.

Naar het oordeel van de Hoge Raad is uit het arrest van het Hof Amsterdam niet afdoende gebleken welke bijzondere omstandigheden rechtvaardigen dat het handelen van Joba, in casu het meewerken aan de vervroeging van de levering van het pand van 23 februari 2007 naar 20 februari 2007, als onrechtmatig moet worden bestempeld door te profiteren van de wanprestatie van Ram Properties. Na verwijzing ligt bij het Hof Den Haag thans de vraag voor in hoeverre de vrijheid van Joba om in haar eigen voordeel te mogen handelen - het nastreven van nakoming van de overeenkomst - moet worden opgeofferd aan de bescherming van de belangen van Tjin-HinTjoe bestaande uit het kunnen uitoefenen van diens bedongen voorkeursrecht.

\section{Conclusie}

De Hoge Raad bevestigt in de onderhavige uitspraak zijn vaste jurisprudentie op het terrein van het profiteren van andermans wanprestatie. In beginsel is de enkele betrokkenheid van een derde bij wanprestatie niet onrechtmatig. Voor onrechtmatigheid is naast wetenschap, ook vereist dat bijzondere omstandigheden aanwezig zijn.

In het arrest Joba/Tjin-Hin-Tjoe stelt de Hoge Raad voorop dat het Joba in beginsel vrijstond om de nakoming van de koopovereenkomst na te streven door vervroeging van de levering. Joba was ten tijde van de totstandkoming van de overeenkomst immers niet bekend met het voorkeursrecht van Tjin- 


\section{Maandblad}

Hin-Tjoe. Ook nu Joba pas in de uitvoeringsfase van de koopovereenkomst - voorafgaand aan de levering - bekend raakte met het voorkeursrecht, mag Joba gebruik maken van haar recht om nakoming van de overeenkomst na te streven. Voor de vraag of Joba in de gegeven omstandigheden door zo te handelen onrechtmatig handelde jegens Tjin-Hin-Tjoe zijn - naast wetenschap van de wanprestatie - bijzondere omstandigheden vereist. Als bijzondere omstandigheid noemt de Hoge Raad in het arrest Joba/Tjin-Hin-Tjoe de omstandigheid dat er sprake is van onevenredigheid tussen het belang bij nakoming van de koopovereenkomst en het belang dat bestaat bij het kunnen uitoefenen van het voorkeursrecht. Andere bijzondere omstandigheden kunnen zijn de ernst en de voorzienbaarheid van het nadeel voor de benadeelde partij, het voordeel van de derde ontstaan door de wanprestatie, de verhouding tussen de profiterende derde en de benadeelde partij en de mate waarin de aangesproken partij de wanprestatie heeft beïnvloed. De betekenis van de bijzondere omstandigheden voor het onrechtmatigheidsoordeel is evenwel een kwestie van casuistiek en zal derhalve van geval tot geval verschillen. 